Article

\title{
Using the Analysis of the Gases Dissolved in Oil in Diagnosis of Transformer Bushings with Paper-Oil Insulation-A Case Study
}

\author{
Tomasz Piotrowski $^{1}\left(\mathbb{D}\right.$, Pawel Rozga $^{1, *(\mathbb{D}}$, Ryszard Kozak ${ }^{2}$ and Zbigniew Szymanski ${ }^{3}$ \\ 1 Institute of Electrical Power Engineering, Lodz University of Technology, Stefanowskiego 18/22, \\ 90-924 Lodz, Poland; tomasz.piotrowski@p.lodz.pl \\ 2 Zrew Transformers S.A., Rokicinska 144, 92-412 Lodz, Poland; Ryszard.Kozak@zrew-tr.pl \\ 3 Energopomiar-Elektryka, Swietokrzyska 2, 44-100 Gliwice, Poland; zbigniew.szymanski@elektryka.com.pl \\ * Correspondence: pawel.rozga@p.lodz.pl; Tel.: +48-42-631-2676
}

Received: 27 November 2020; Accepted: 18 December 2020; Published: 19 December 2020

\begin{abstract}
The article describes a case study when the voltage collapse during lightning impulse tests of new power transformers was noticed and when the repeated tests finished with a positive result. The step-by-step process of reaching the conclusion on the basis of dissolved gas analysis (DGA) as a key method of the investigations was presented. The considerations on the possible source of the analysis showed that the Duval triangle method, used in the analysis of the concentration of gases dissolved in oil samples taken from bushings, more reliably and unambiguously than the ratio method recommended in the IEC 60599 Standard, indicated a phenomenon which was identified in the insulation structure of bushings analyzed. Additionally, the results from DGA were found to be consistent with an internal inspection of bushings, which showed a visible trace of discharge on the inside part of the epoxy housing, as a result of the lightning induced breakdown.
\end{abstract}

Keywords: dissolved gas analysis; oil-paper insulation; high voltage bushing

\section{Introduction}

The dissolved gas analysis (DGA) is the most widely used method in the diagnosis of power transformers. There are many publications confirming the usefulness of this method as well as its effectiveness, as for instance in [1-7]. The works mentioned showed that with the application of the DGA method, it is possible to detect a thermal or electrical defect of the transformer's insulation system at a stage that will prevent the final damage of the unit. However, in the case of bushings with the oil-paper insulation (OIP), the basic method of cyclical diagnosis according to [8] and based on the service experience, is the measurement of capacitance $C$ and dielectric dissipation factor $(\tan \delta)$, then the infrared scanning, and finally DGA. A limitation of the use of the DGA method lies in the need to respect the special procedures of taking the oil sample from the bushing, which, without a special commitment, may cause the bushings damage and the necessity of the transformer to be switched off. Hence, the literature data on applying the DGA method in the bushings diagnosis are very limited [9-13]. In [9], Malpure et al. analyzed the results of the DGA of bushings of three transformer units. The authors considered DGA as a supporting tool for typically used diagnostic methods based on capacitance and $\tan \delta$ measurements of bushings. In all cases, the data concerning DGA indicated the occurrence of partial discharges (PDs) in bushings which were confirmed by on-site PD tests. The authors' conclusion was that the DGA supplemented by electrical tests may be significantly helped in the diagnosis of bushings when electrical tests did not give unambiguous results. In turn, Mohseni et al. [10] proposed a precise simulation as well as practical analyses demonstrating the impact 
of bushing faults on the frequency response analysis (FRA) signature of the transformer and connected the simulation results with a real object- $132 \mathrm{kV}$ power transformer, for which the FRA results were set with the results of DGA. The conclusions found by the authors were that the bushing faults have an impact on the FRA signature and DGA and both methods may supplement the classical approach based on $C$ and $\tan \delta$. In [11], the authors described the case studies of the series of OIP bushings, in which gas concentrations were measured and DGA analyses were done as additional methods supporting the above mentioned conventional methods and dielectric frequency response (DFR), which was also applied as a diagnostic tool in the assessment of the bushings condition. The general conclusions were that DGA may strengthen the diagnosis elaborated on the basis of more conventional methods, however, with a lower level of success than DFR. In [12], the fault diagnosis and tear-down analysis of five $500 \mathrm{kV}$ OIP transformer bushings were presented. In the authors' considerations, next to the capacitance and $\tan \delta$ measurements, the frequency domain spectroscopy (FDS) method in combination with DGA as a supplementary field diagnostic test were applied. The tests performed indicated the effectiveness of adopting FDS in combination with DGA. In particular, this effectiveness was visible when the partial discharge-based defect took place. In the work of Ensico et al. [13], DGA was also used as the supporting method in the diagnosis of six high voltage bushings, which were removed preventively from the service. Next to the capacitance and $\tan \delta$ measurements, the other laboratory techniques as a partial discharge measurement and DFR were applied together with DGA. The authors found that DGA based the diagnosis indicated with a success activity of partial discharges, which confirmed the data from other laboratory measurements. In the case of other literature reports, DGA was noticed as a useful diagnostic tool for the assessment of the bushings condition.

The general rules concerning the detection and characterization of faults in bushings, using the dissolved gas analysis, are the same as in the case of power transformers. This means that in the first step of the condition assessment of bushings it is necessary to check whether the measured gas concentrations exceed the typical values, and if this takes place, the nature of the defect can be determined in the next step.

According to the IEC 60599 Standard [14], the data presented in Table 1 are proposed to be considered as typical values.

Table 1. The 95\% typical concentration values (ppm) in bushings proposed in the IEC 60599 Standard.

\begin{tabular}{ccccccc}
\hline $\mathbf{H}_{2}$ & $\mathrm{CO}$ & $\mathrm{CO}_{2}$ & $\mathrm{CH}_{4}$ & $\mathrm{C}_{2} \mathbf{H}_{6}$ & $\mathrm{C}_{2} \mathbf{H}_{4}$ & $\mathrm{C}_{2} \mathbf{H}_{2}$ \\
\hline 140 & 1000 & 3400 & 40 & 70 & 30 & 2 \\
\hline
\end{tabular}

In turn, on the local market, the typical values of gas concentrations in bushings are proposed to be accepted according to the regulations [15], as presented in Table 2. In the case of carbon monoxide and ethylene, they are a bit more restrictive than those proposed in [14].

Table 2. The 95\% typical concentration values (ppm) in bushings proposed in the Framework Instruction of Transformer Operation (Poland) [15].

\begin{tabular}{ccccccc}
\hline $\mathrm{H}_{2}$ & $\mathrm{CO}$ & $\mathrm{CO}_{2}$ & $\mathrm{CH}_{4}$ & $\mathrm{C}_{2} \mathrm{H}_{6}$ & $\mathrm{C}_{2} \mathrm{H}_{4}$ & $\mathrm{C}_{2} \mathbf{H}_{2}$ \\
\hline 140 & 600 & 3400 & 40 & 70 & 15 & 2 \\
\hline
\end{tabular}

However, CIGRE, in brochure no. 771 [16], presented $95 \%$ of typical gas concentrations determined on the basis of data collected from surveys carried out in several European countries. These data take into account the nominal voltage or construction of the bushings. The values proposed are significantly higher than these from the IEC 60599 Standard. The graphical representation of these data based on [16] are shown in Figure 1. 


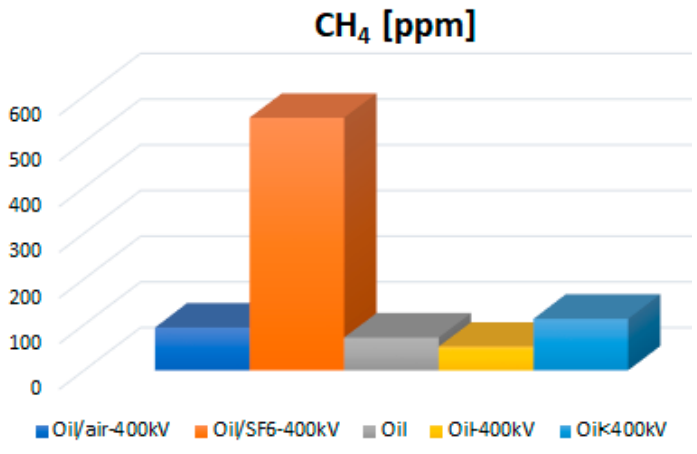

(a)

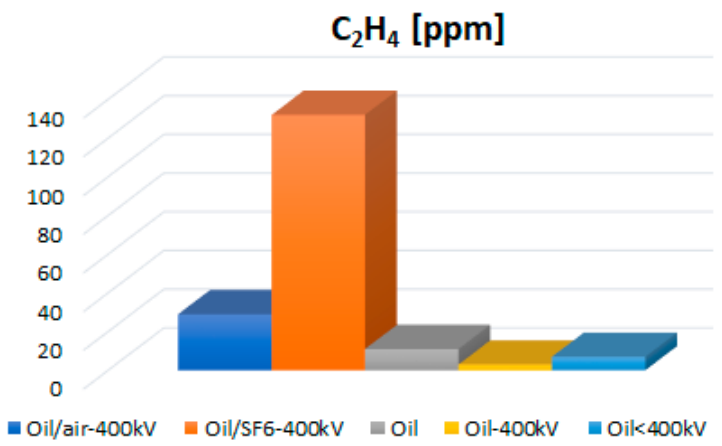

(c)

\section{CO [ppm]}

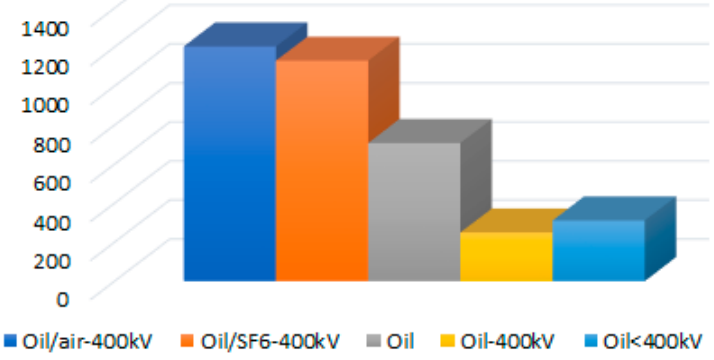

(e)

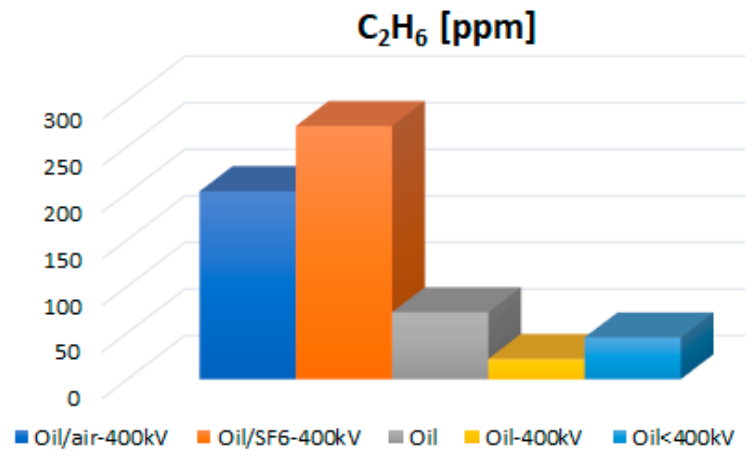

(b)

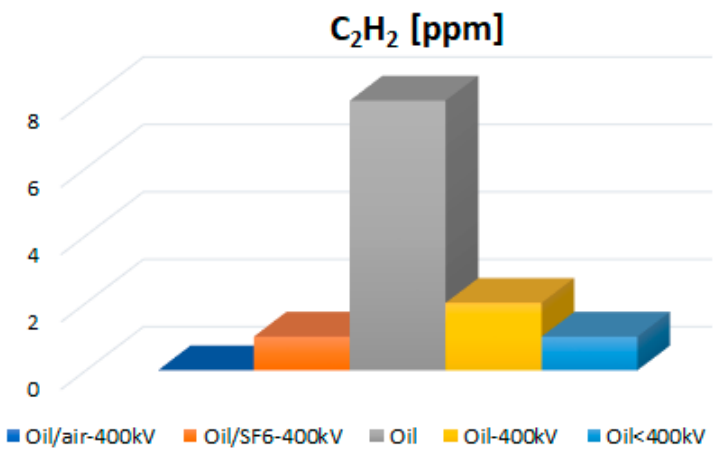

(d)

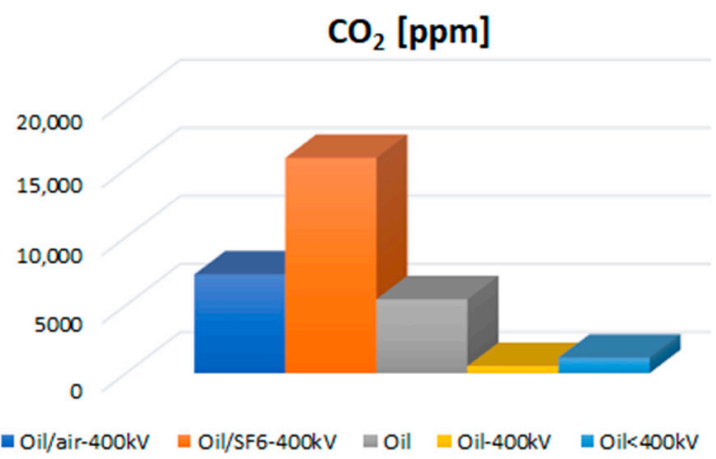

$(\mathbf{f})$

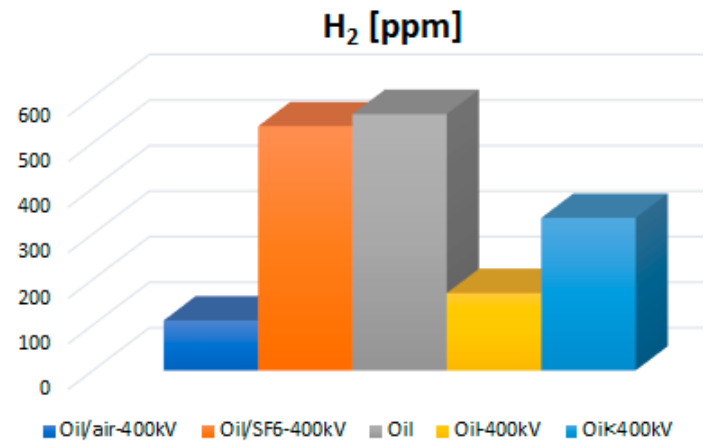

$(\mathrm{g})$

Figure 1. The $95 \%$ typical values of gas concentrations in bushings proposed in the CIGRE brochure 771: (a) $\mathrm{CH}_{4}$, (b) $\mathrm{C}_{2} \mathrm{H} 6$, (c) $\mathrm{C}_{2} \mathrm{H}_{4}$, (d) $\mathrm{C}_{2} \mathrm{H}_{2}$, (e) $\mathrm{CO}$, (f) $\mathrm{CO}_{2}$, (g) $\mathrm{H}_{2}$. 
There are five typical kinds of faults detected in the case of bushings. They are set in Table 3 together with the causes of these faults and the corresponding characteristic gases dissolved in oil.

Table 3. Fault types detected in bushings on the basis of the analysis of gases dissolved in oil [16,17].

\begin{tabular}{|c|c|c|c|}
\hline No. & Gases & Causes of Gas Generation & Fault Type \\
\hline 1 & $\mathrm{H}_{2}, \mathrm{CH}_{4}$ & $\begin{array}{c}\text { Discharges in gas-filled cavities resulting from humidity in } \\
\text { paper, poor impregnation, oil supersaturation, } \\
\text { or contamination }\end{array}$ & Partial discharges \\
\hline 2 & $\mathrm{H}_{2}, \mathrm{C}_{2} \mathrm{H}_{2}$ & $\begin{array}{l}\text { Occasional sparking due to the floating potential, } \\
\text { sparking due to loose connections at capacitive tap, arcing in } \\
\text { static shielding connections, tracking in paper }\end{array}$ & Low-energy discharges \\
\hline 3 & $\mathrm{C}_{2} \mathrm{H}_{2}, \mathrm{C}_{2} \mathrm{H}_{4}$ & $\begin{array}{c}\text { Continuous sparking in the oil between poorly connected } \\
\text { elements of different potentials, localized short-circuits } \\
\text { between capacitive stress grading foils }\end{array}$ & High-energy discharges \\
\hline 4 & $\mathrm{C}_{2} \mathrm{H}_{4}, \mathrm{C}_{2} \mathrm{H}_{6}$ & Overheating of wire in the oil & Oil overheating \\
\hline 5 & $\mathrm{CO}, \mathrm{CO}_{2}$ & $\begin{array}{l}\text { Overheating of wire in contact with paper, overheating due } \\
\text { to dielectric losses }\end{array}$ & Paper overheating \\
\hline
\end{tabular}

According to [14], knowing the values of the concentrations of gases dissolved in the oil, the nature of the fault can be recognized on the basis of a simplified analysis of the following values of characteristic ratios: $\mathrm{C}_{2} \mathrm{H}_{2} / \mathrm{C}_{2} \mathrm{H}_{4}, \mathrm{CH}_{4} / \mathrm{H}_{2}, \mathrm{C}_{2} \mathrm{H}_{4} / \mathrm{C}_{2} \mathrm{H}_{6}, \mathrm{CO}_{2} / \mathrm{CO}$. The criteria used in this field are presented in Table 4.

Table 4. Simplified interpretation scheme of gas ratios for bushings proposed in the IEC 60599 Standard.

\begin{tabular}{ccccc}
\hline Fault & $\mathrm{C}_{2} \mathrm{H}_{2} / \mathrm{C}_{2} \mathrm{H}_{4}$ & $\mathrm{CH}_{4} / \mathrm{H}_{2}$ & $\mathrm{C}_{2} \mathrm{H}_{4} / \mathrm{C}_{2} \mathrm{H}_{6}$ & $\mathrm{CO}_{2} / \mathrm{CO}$ \\
\hline $\mathrm{PD}$ & & $<0.07$ & & \\
$\mathrm{D}$ & $>1$ & & $>1$ & \\
$\mathrm{~T}$ & & & $<1$ or $>20$ \\
$\mathrm{TP}$ & & & \\
PD-Partial Discharge, D-Discharges, T-Thermal Fault, TP-Thermal Fault in Paper.
\end{tabular}

In this case, when a more precise diagnosis is needed or when more than one fault is indicated, the relationships accepted for power transformers should be applied, as presented in Table 5 .

Table 5. Interpretation scheme of gas ratios for bushings proposed in the IEC 60599 Standard.

\begin{tabular}{cccc}
\hline Fault & $\mathrm{C}_{\mathbf{2}} \mathbf{H}_{\mathbf{2}} / \mathrm{C}_{\mathbf{2}} \mathbf{H}_{\mathbf{4}}$ & $\mathrm{CH}_{\mathbf{4}} / \mathbf{H}_{\mathbf{2}}$ & $\mathrm{C}_{\mathbf{2}} \mathbf{H}_{\mathbf{4}} / \mathbf{C}_{\mathbf{2}} \mathbf{H}_{\mathbf{6}}$ \\
\hline Partial discharges (PD) & $\mathrm{NS}$ & $<0.1$ & $<0.2$ \\
Discharges of low Energy (D1) & $>1$ & $0.1-0.5$ & $>1$ \\
Discharges of high Energy (D2) & $0.6-2.5$ & $0.1-1$ & $>2$ \\
Thermal fault T $<300^{\circ} \mathrm{C}(\mathrm{T} 1)$ & $\mathrm{NS}$ & $>1$ but NS & $<1$ \\
Thermal fault $300{ }^{\circ} \mathrm{C}<\mathrm{T}<700^{\circ} \mathrm{C}(\mathrm{T} 2)$ & $<0.1$ & $>1$ & $1-4$ \\
Thermal fault $\mathrm{T}>700^{\circ} \mathrm{C}(\mathrm{T} 3)$ & $<0.2$ & $>1$ & $>4$ \\
\hline
\end{tabular}

NS-value is non-significant.

In a number of cases, ratio methods, including the one recommended in the IEC 60559 Standard, cannot identify the nature of a potential fault for the measured gas concentrations. In such a case, it is recommended to use the well-known and widely used method of Duval's triangle in the basic version (version 1) [18,19], which is used not only in the diagnostics of power transformers, but also in the case of bushings.

Based on the above considerations, the authors decided to present further in this paper a case study when the voltage collapse during the lightning impulse tests of new power transformers was noticed and when the repeated tests finished with a positive result. The step-by-step process of reaching 
the conclusion on the source of the failed test, which was found in the bushings, was presented based on DGA as a key method of the investigations.

\section{Case Study}

During the tests of $115 / 16.5 \mathrm{kV}, 16 \mathrm{MVA}$, YNd11 power transformer by a negative standard lightning impulse voltage ( $1.2 \mu \mathrm{s} \pm 30 \% / 50 \mu \mathrm{s} \pm 20 \%$ ) of peak voltage equal to $550 \mathrm{kV}$, the voltage collapsed on the voltage waveform tail when phase $1 \mathrm{U}$ was tested. The transformer manufacturer as well as the buyer agreed to repeat the test, and this time it finished with success. A confirmation of the negative and positive lightning test of phase $1 \mathrm{U}$ is shown in Figure 2, where the course registered during the failed test is presented in Figure $2 \mathrm{a}$ and the course registered during the repeated test is presented in Figure 2b, respectively. Herein, it is important to point out that the other phases passed the lightning test positively. Therefore, the courses corresponding to these phases were similar to the course presented in Figure 2b.

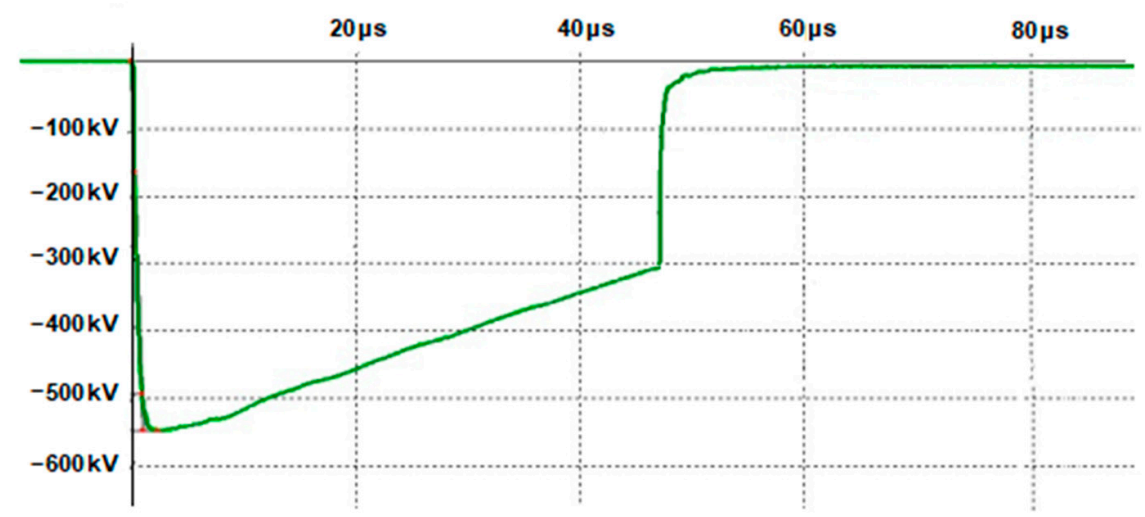

(a)

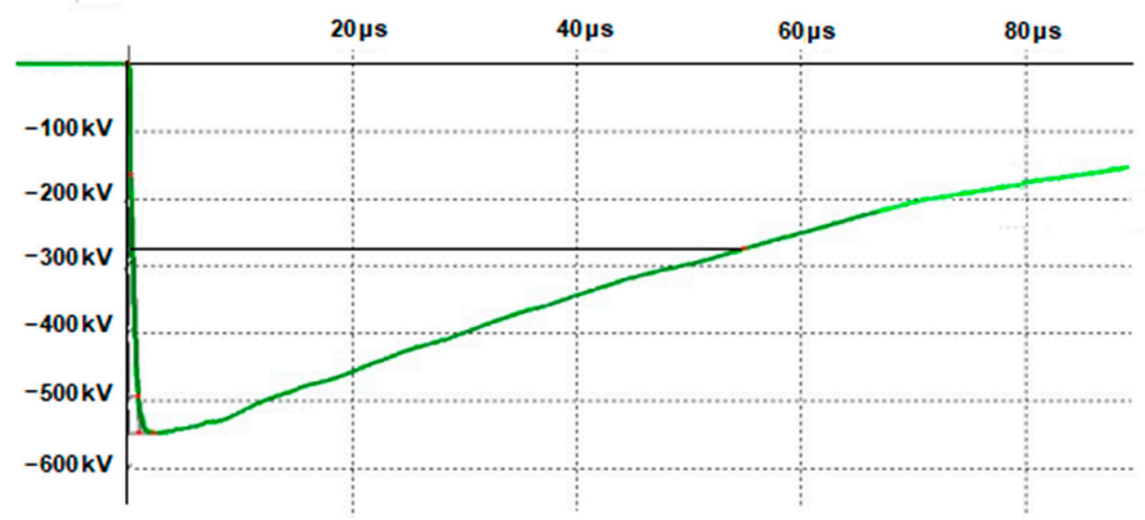

(b)

Figure 2. Voltage waveforms registered during the test by the lightning impulse voltage $1.2 \mu \mathrm{s} \pm 30 \% / 50 \mu \mathrm{s} \pm 20 \%$ and peak value of $550 \mathrm{kV}$ : (a) when the lightning impulse test was failed, (b) when the test was positive.

Despite the positive result of the second attempt, it was decided to conduct a study to find the cause of the failure of the first test on the $1 \mathrm{U}$ phase. The scope of the investigation included:

(1) Checking the testing setup;

(2) Analysis of the transformer construction;

(3) Analysis of technology of the transformer manufacturing;

(4) Tests and external inspection of the transformer. 
The investigation performed did not show any inaccuracies in the testing setup as well as any abnormalities at the lightning test conducted. However, it confirmed the correctness of the design process and of all the steps in the process of manufacturing, including drying of cellulose insulation, filling the transformer with oil, and the impregnation process. Additionally, the oil sample was taken from the transformer in order to determine the concentrations of gases dissolved in oil. The results in this field together with data from the measurements performed before the lightning tests are quoted in Table 6.

Table 6. Gas concentrations measured for the oil samples taken from the transformer tank before and after the lightning impulse (LI) test.

\begin{tabular}{ccc}
\hline \multirow{2}{*}{ Gas } & \multicolumn{2}{c}{ Gas Concentrations } \\
\cline { 2 - 3 } & Before LI Test & After LI Test \\
\cline { 2 - 3 } & $\mathbf{( p p m )}$ & $\mathbf{( p p m )}$ \\
\hline $\mathrm{H}_{2}$ (hydrogen) & 0.0 & 0.0 \\
$\mathrm{C}_{2} \mathrm{H}_{2}$ (acetylene) & 0.0 & 0.0 \\
$\mathrm{C}_{2} \mathrm{H}_{4}$ (ethylene) & 0.0 & 0.0 \\
$\mathrm{C}_{2} \mathrm{H}_{6}$ (ethane) & 0.0 & 0.0 \\
$\mathrm{C}_{3} \mathrm{H}_{6}$ (propylene) & 0.0 & 0.0 \\
$\mathrm{C}_{3} \mathrm{H}_{8}$ (propane) & 0.0 & 0.0 \\
$\mathrm{CH}_{4}$ (methane) & 0.0 & 0.1 \\
$\mathrm{CO}($ carbon monoxide) & 4.3 & 5.8 \\
$\mathrm{CO}$ (carbon dioxide) & 64.1 & 75.0 \\
Air & 7027.3 & 6944.1 \\
Sum of total combustion gases TCG & 4.3 & 5.9 \\
\hline
\end{tabular}

As we can see from the table, the analysis of the measured gas concentrations did not indicate any problems. Hence, in addition, the HV bushing of the $115 \mathrm{kV}$ side of the phase, in which the voltage collapsed during the lightning test (phase $1 \mathrm{U}$ ), was tested. The dielectric dissipation factor $\operatorname{tg} \delta$ and the insulator capacity were measured and, which is not a common practice, an oil sample was taken from the considered bushing to determine the concentration of gases dissolved in it. The results concerning $\operatorname{tg} \delta$ and capacity, as well as the gas concentration measurements were presented in Table 7 and 8 , respectively.

Table 7. Results of the measurements of $\operatorname{tg} \delta$ and capacity for the bushing of the phase $1 \mathrm{U}$ set with the values of these parameters given by the manufacturer.

\begin{tabular}{cccccc}
\hline \multirow{2}{*}{ Capacity Tested } & Testing Voltage & \multicolumn{2}{c}{$\begin{array}{c}\text { Values Measured after the LI } \\
\left.\text { Test (Measurement at } 2{ }^{\circ} \mathbf{C}\right)\end{array}$} & $\begin{array}{c}\text { Values Given by the Manufacturer } \\
\text { (Measurement at 24 }{ }^{\circ} \mathrm{C} \text { ) }\end{array}$ \\
\cline { 2 - 6 } & & $\mathrm{C}$ & $\operatorname{tg} \delta$ & $\mathrm{C}$ & $\operatorname{tg} \delta$ \\
\cline { 2 - 6 } & {$[\mathrm{kV}]$} & {$[\mathrm{pF}]$} & {$[\%]$} & {$[\mathrm{pF}]$} & {$[\%]$} \\
\hline $\mathrm{C} 1$ & 10 & 165.2 & 0.267 & 169.0 & 0.240 \\
\hline
\end{tabular}

As it is clearly seen in the quoted table, the results concerning $\operatorname{tg} \delta$ and capacity did not indicate that the bushing considered might be damaged. Additionally, the measured value of the oil moisture (6.6 ppm) did not indicate on its potential contribution to the causes of the phenomena observed during the lightning impulse tests.

The content analysis of Table 8 shows an exceedance of the typical values given by the IEC 60599 Standard by hydrogen, methane, ethylene, and acetylene. Additionally, the mentioned gases exceed the typical values used locally in Poland [15]. Therefore, the values from Table 8 indicate that the cause of voltage collapse during the lightning test of the power transformer could be due to the defect of the bushing. A simplified analysis of the values of the characteristic ratios in accordance with the guidelines of the IEC 60599 Standard $\left(\mathrm{C}_{2} \mathrm{H}_{2} / \mathrm{C}_{2} \mathrm{H}_{4}=753 / 791=0.95 ; \mathrm{CH}_{4} / \mathrm{H}_{2}=672 / 965=0.70\right.$; 
$\left.\mathrm{C}_{2} \mathrm{H}_{4} / \mathrm{C}_{2} \mathrm{H}_{6}=791 / 67=11.24 ; \mathrm{CO}_{2} / \mathrm{CO}=1769 / 141=12.55\right)$ was indicated on the thermal fault. However, a very high concentration of acetylene and simultaneously the value of $\mathrm{C}_{2} \mathrm{H}_{2} / \mathrm{C}_{2} \mathrm{H}_{4}$ ratio close to 1 might also indicate the discharges as a potential cause of the voltage collapse during the lightning tests. Additionally, applying a full version of the ratio method recommended by the IEC 60599 Standard clearly identified the discharges of high energy (D2) in the bushing considered, which is confirmed by the data in Table 9 .

Table 8. Results of the measurements of the gas concentrations in the oil sample taken from the bushing of the $1 \mathrm{U}$ phase after the lightning tests (exceedance of the typical values is marked in bold font).

\begin{tabular}{cccc}
\hline \multirow{2}{*}{ Gas } & \multicolumn{3}{c}{ Gas Concentrations } \\
\cline { 2 - 4 } & Measured & Typical Acc. to [14] & Typical Acc. to [15] \\
\cline { 2 - 4 } & $\mathbf{p p m}$ & $\mathbf{p p m}$ & ppm \\
\hline $\mathrm{H}_{2}$ (hydrogen) & 965 & 140 & 140 \\
$\mathrm{CH}_{4}$ (methane) & 672 & 40 & 40 \\
$\mathrm{C}_{2} \mathrm{H}_{6}$ (ethane) & 67 & 70 & 70 \\
$\mathrm{C}_{2} \mathrm{H}_{4}$ (ethylene) & 791 & 30 & 15 \\
$\mathrm{C}_{2} \mathrm{H}_{2}$ (acetylene) & 753 & 2 & 2 \\
$\mathrm{C}_{3} \mathrm{H}_{8}$ (propane) & 5 & - & - \\
$\mathrm{C}_{3} \mathrm{H}_{6}$ (propylene) & 138 & - & - \\
$\mathrm{CO}_{(\text {carbon monoxide) }}$ & 141 & 1000 & 600 \\
$\mathrm{CO}_{2}$ (carbon dioxide) & 1769 & 3400 & 3400 \\
Sum of total combustion gases TCG & 3532 & - & - \\
\hline
\end{tabular}

Table 9. The values of characteristic ratios required to determine the discharge of high energy as per the IEC 60599 Standard and the values calculated on the basis of measurement data.

\begin{tabular}{cccc}
\hline & $\mathrm{C}_{2} \mathrm{H}_{2} / \mathrm{C}_{2} \mathrm{H}_{4}$ & $\mathrm{CH}_{4} / \mathrm{H}_{2}$ & $\mathrm{C}_{2} \mathrm{H}_{4} / \mathrm{C}_{2} \mathrm{H}_{6}$ \\
\hline Required limits & $0.6-2.5$ & $0.1-1$ & $>2$ \\
Calculated values & 0.95 & 0.70 & 11.24 \\
\hline
\end{tabular}

Similarly, the analysis made using the basic form of Duval's triangle indicated the high energy discharges (D2) in the bushing. The results in this field are presented in Figure 3.

Taking into account the conclusion from the quoted analyses and the lack of visible effects of discharges, the disassembly of the bushing was made and its internal inspection was ordered. On its basis, the discharge occurrence was confirmed-the arcing developed along the inner surface of the epoxy insulator from the tube to the flange at ground potential, as shown in Figure 4. 


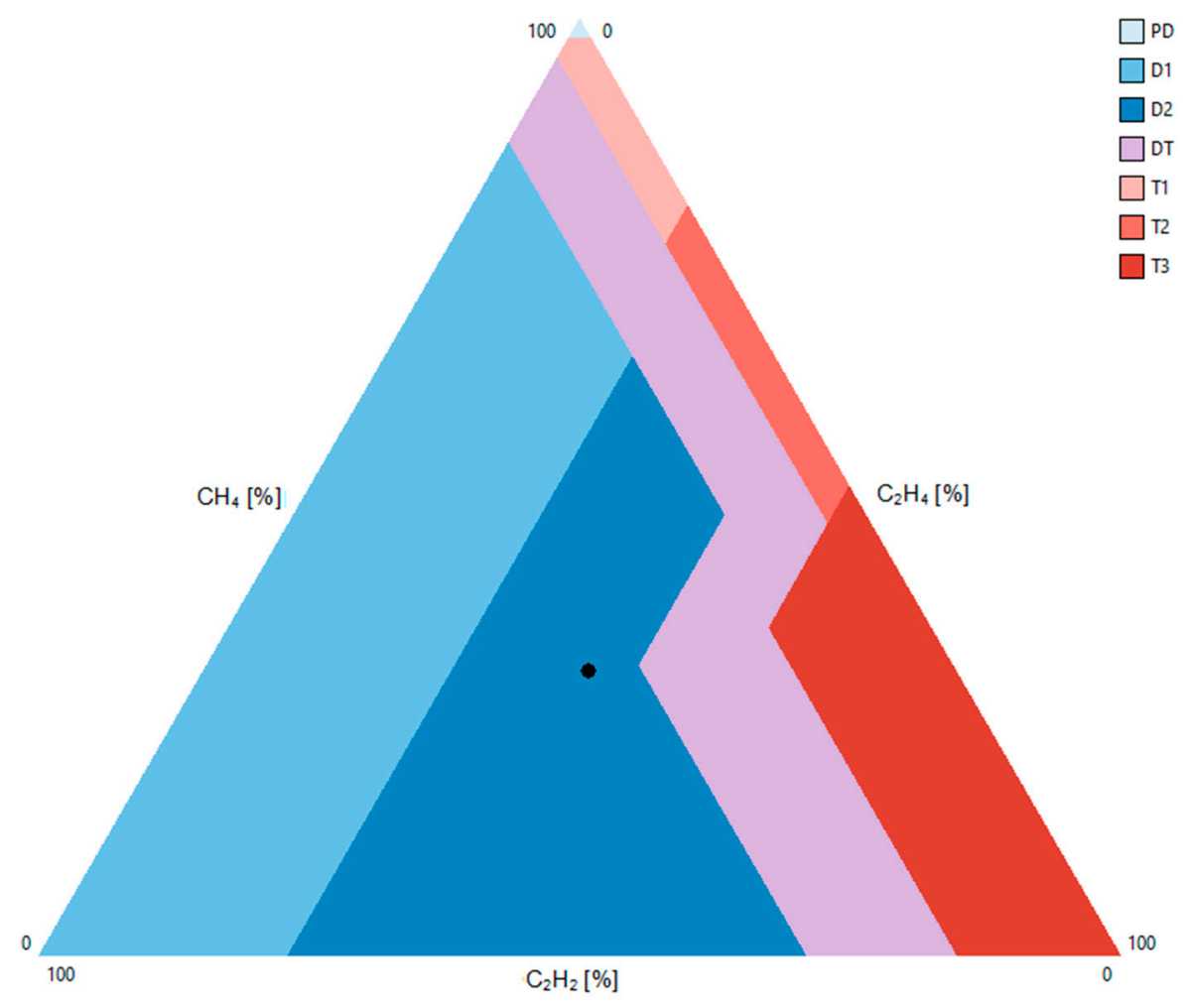

Figure 3. The result of the analysis using the basic form of Duval's triangle.
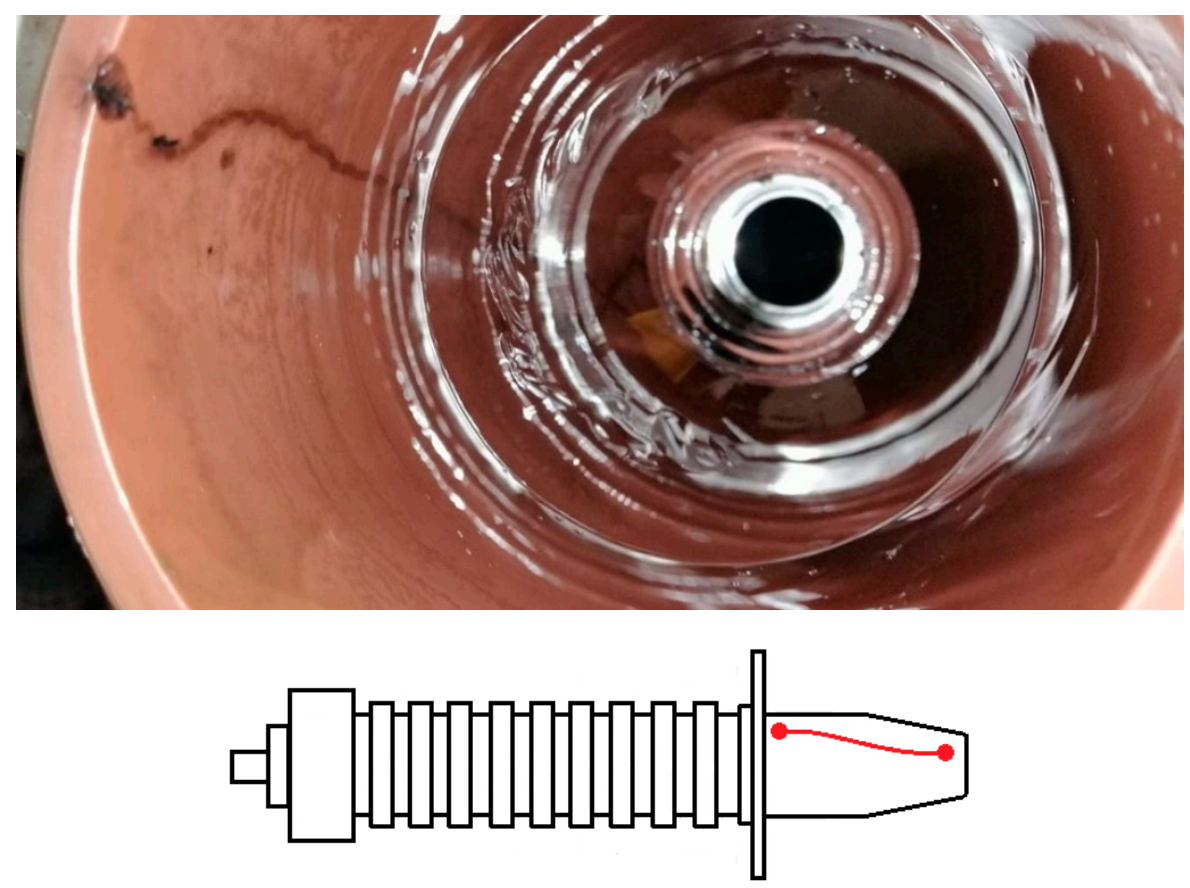

Figure 4. Visible trace of the discharge on the inside part of the epoxy housing (top) together with the illustrative sketch showing the development path of the discharge (bottom).

Considering different options of the noticed situation, it was assumed that the direct cause of the discharge formation was an air bubble present in the lower part of the bushing. It was created as a result of an incorrect way of transporting the bushing and its storage. This assumption was confirmed by the noticed way of arranging the bushing in the transport crate, as shown in Figure 5. The photograph from this figure also shows a badly placed information label. The bushing, after placing in the transport 
crate, should have an oil level indicator downward, towards the bottom of the crate and the information label on the bushing head should be placed on the opposite side of the indicator.
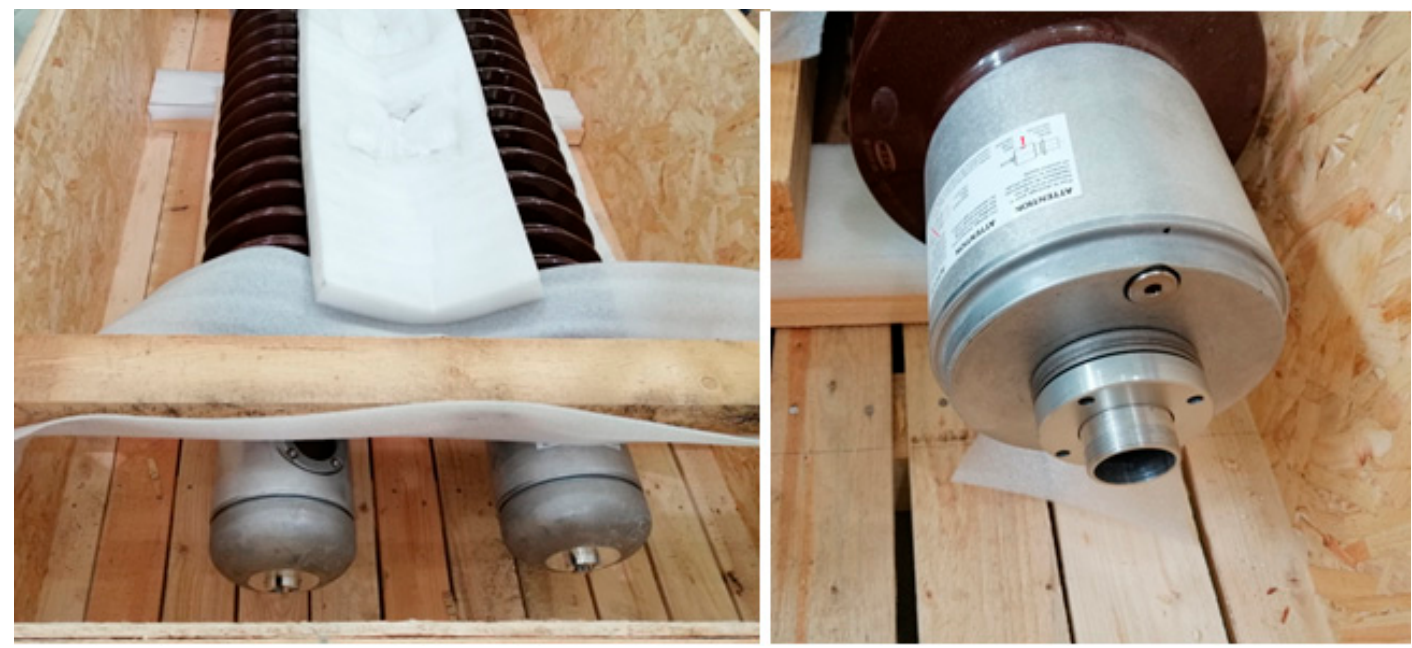

Figure 5. Wrong method of bushing transportation (the photo on the right shows the incorrect position of the information label).

The source of the agglomerated air could also be an excessive fit of the capacitor part of the bushing inside the housing (Figure 6). As a result, after filling the bushing with oil, the air could not be released.

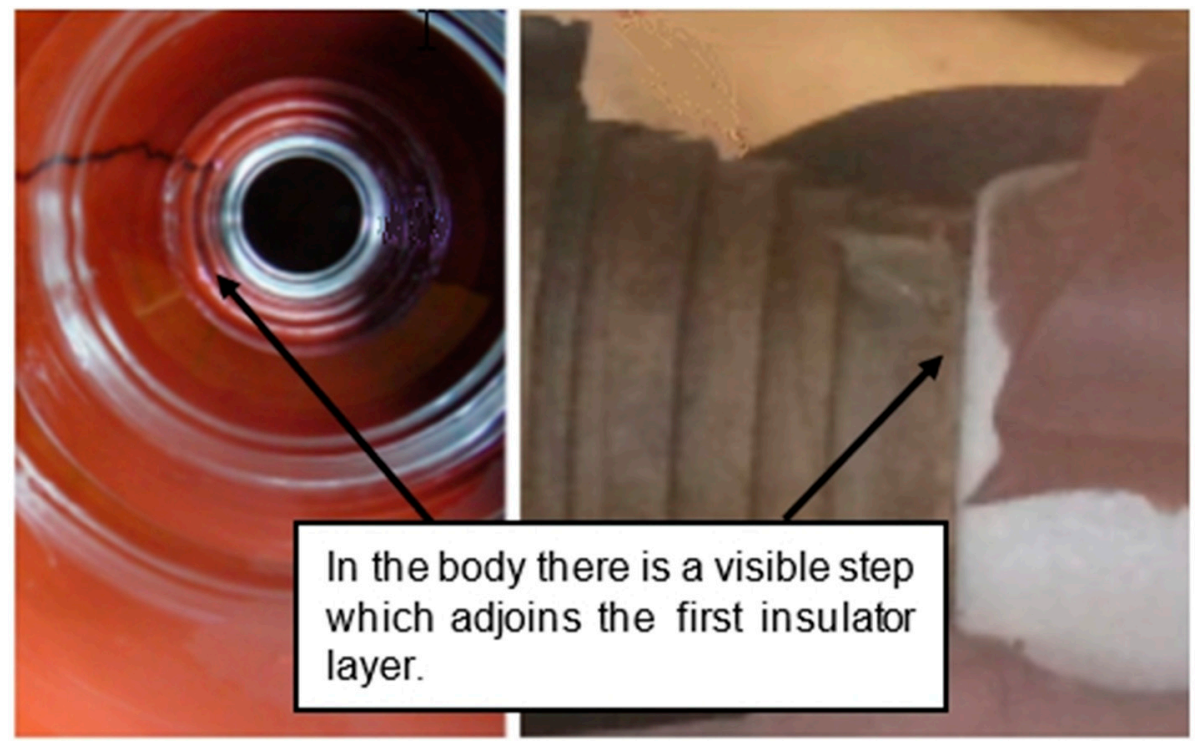

Figure 6. Excessive fit of the capacitor part of the bushing inside the housing.

The relative dielectric permittivity of gas $\left(\varepsilon_{\text {gas }} \approx 1\right)$ in the bubble is more than twice lower than that of oil ( $\varepsilon_{\mathrm{oil}} \approx 2.2$ ), which results in the presence of proportionally higher values of the electric field stress (simply $\mathrm{E}_{\text {gas }}=\mathrm{E}_{\mathrm{oil}} \cdot \varepsilon_{\mathrm{oil}} / \varepsilon_{\text {gas }}$ ) and significantly facilitates the formation and development of discharges. After the occurrence of discharge during the first lightning impulse test, the air bubble disappeared and the strength of the insulation system intended by the designer was achieved, which resulted in the successful completion of the repeated test.

An identical situation, as described above, happened for four more transformers equipped with the same types of bushings. Similarly, as in the case mentioned above, only the bushings of the selected phases did not pass the first lightning test. Table 10 summarizes the values of the measured gas 
concentrations from the bushings installed in these transformer phases, in which the voltage collapsed during the lightning test.

Table 10. Results of the measurements of gas concentrations in oil samples taken from the bushings after the lightning impulse tests (exceedance of the typical values is marked in bold font).

\begin{tabular}{|c|c|c|c|c|c|}
\hline \multirow{4}{*}{ Gas } & \multicolumn{5}{|c|}{ Gas Concentrations } \\
\hline & \multicolumn{4}{|c|}{ Measured } & \multirow{2}{*}{$\begin{array}{c}\text { Typical Acc. to }[14] \\
-\end{array}$} \\
\hline & 1 & 2 & 3 & 4 & \\
\hline & ppm & ppm & ppm & ppm & ppm \\
\hline $\mathrm{H}_{2}$ (hydrogen) & 936.5 & 747 & 547.1 & 71.3 & 140 \\
\hline $\mathrm{CH}_{4}$ (methane) & 1032 & 814 & 562.8 & 57.3 & 40 \\
\hline $\mathrm{C}_{2} \mathrm{H}_{6}$ (ethane) & 90.4 & 63.2 & 63.7 & 4.4 & 70 \\
\hline $\mathrm{C}_{2} \mathrm{H}_{4}$ (ethylene) & 1172 & 851 & 733.7 & 59.5 & 30 \\
\hline $\mathrm{C}_{2} \mathrm{H}_{2}$ (acetylene) & 1413 & 695 & 707.6 & 68.6 & 2 \\
\hline $\mathrm{C}_{3} \mathrm{H}_{8}$ (propane) & 13.6 & 7.7 & 7.6 & 0.9 & - \\
\hline $\mathrm{C}_{3} \mathrm{H}_{6}$ (propylene) & 165 & 320 & 208 & 5 & - \\
\hline $\mathrm{CO}$ (carbon monoxide) & 0 & 42.5 & 18 & 8.2 & 1000 \\
\hline $\mathrm{CO}_{2}$ (carbon dioxide) & 470 & 482 & 469.8 & 262.7 & 5437 \\
\hline Sum of total combustion gases TCG & 4822 & 3540 & 2848 & 275.2 & - \\
\hline
\end{tabular}

When analyzing Table 10, it can be noticed that in all cases the concentration of methane, ethylene, and acetylene exceeded the typical values recommended by the IEC 60599 Standard. In some cases, the typical values of hydrogen and ethane concentrations were also exceeded. The use of the full version of the ratio method clearly indicated the occurrence of high-energy discharges (D2) only in case 4. However, taking into account the obtained ratio values, as shown in Table 11, it is reasonable to suppose that in other cases the discharge also occurred.

Table 11. The values of characteristic ratios required to determine the discharge of high energy as per the IEC 60599 Standard and the values calculated on the basis of measurement data.

\begin{tabular}{cccccc}
\hline & Case No. Acc. to Table 10 & $\mathbf{C}_{2} \mathbf{H}_{2} / \mathbf{C}_{2} \mathbf{H}_{4}$ & $\mathbf{C H}_{4} / \mathbf{H}_{2}$ & $\mathbf{C}_{2} \mathbf{H}_{4} / \mathbf{C}_{2} \mathbf{H}_{\mathbf{6}}$ & Fault \\
\hline Required limits & - & $0.6-2.5$ & $0.1-1$ & $>2$ & - \\
& 1 & 1.21 & 1.10 & 12.96 & $\mathrm{NR}$ \\
Calculated values & 2 & 0.82 & 1.09 & 13.47 & $\mathrm{NR}$ \\
& 3 & 0.96 & 1.03 & 11.52 & $\mathrm{NR}$ \\
& 4 & 1.15 & 0.80 & 13.52 & $\mathrm{D} 2$ \\
\hline
\end{tabular}

In turn, when using Duval's triangle for the analysis of the gas concentrations in all cases, the discharges of high energies were confirmed, as shown in Figure 7. 


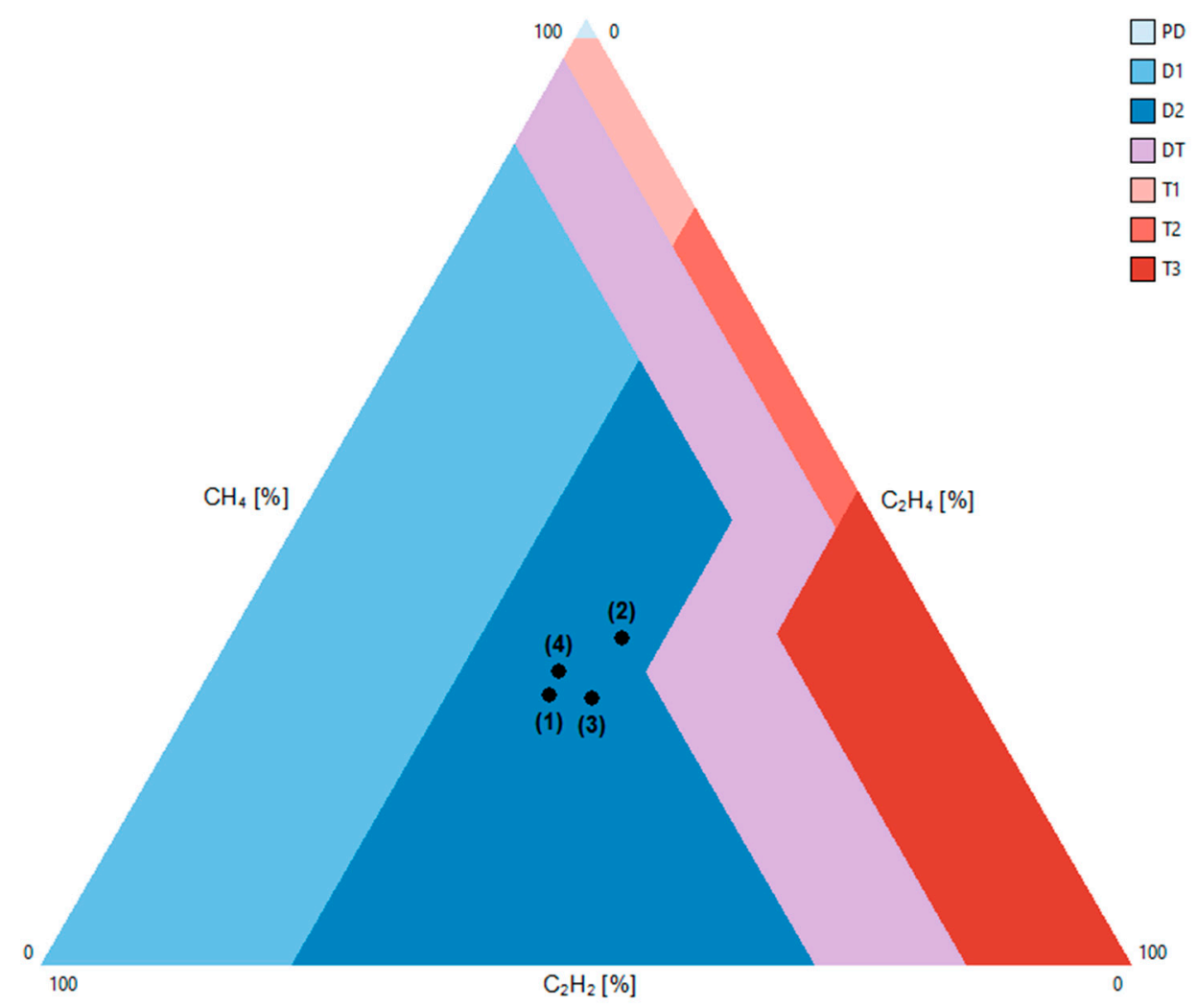

Figure 7. Faults detected in the bushing using Duval's triangle (the numbers in the brackets correspond to the numbers of cases in Table 10).

\section{Conclusions}

On the basis of the considerations presented in this paper, the following conclusions may be formed:

(1) The analysis of gases dissolved in oil taken from oil-paper-insulated transformer bushings played a key role in the investigations, which led to finding the source of failure of the first lightning test.

(2) Within the analysis performed, the Duval triangle method proved to be more reliable than the ratio method recommended in the IEC 60599 Standard, indicating unambiguously a phenomenon that took place in the insulation structure of the bushings. It is confirmed by the results concerning the bushings of four additionally analyzed cases of transformers where the Duval triangle method indicated the D2 type defect in all cases, while the ratio method in three cases did not recognize the defect.

(3) DGA may be significantly helped in the diagnosis of bushing faults when typical electrical tests (C and $\tan \delta$ ) did not give unequivocal results.

(4) The practical conclusion from the analyses carried out is an indication of paying special attention to the way the bushings are stored and transported. An incorrect approach in this field may cause the occurrence of air bubbles in some parts of the bushing and the generation of unexpected discharges, especially of high energies. Such discharge inside the bushing may result in its physical destruction and the necessity of incurring costs to purchase a new one.

Author Contributions: Conceptualization, T.P.; methodology, T.P.; validation, T.P. and P.R.; formal analysis, T.P., P.R., R.K., and Z.S.; data curation, T.P., R.K., and Z.S.; writing-original draft preparation, T.P., P.R., R.K., and Z.S.; writing - review and editing, T.P. and P.R.; visualization, T.P. and R.K.; supervision, T.P. and P.R. All authors have read and agreed to the published version of the manuscript.

Funding: This research received no external funding.

Conflicts of Interest: The authors declare no conflict of interest. 


\section{References}

1. Rozga, P.; Piotrowski, T.; Kozak, R. Experiences with detection of transformer failure based on insulating oil tests. In Proceedings of the 19th IEEE International Conference on Dielectric Liquids (ICDL), Manchester, UK, 25-29 June 2017. [CrossRef]

2. Kunicki, M.; Cichon, A.; Borucki, S. Measurements on partial discharge in on-site operating power transformer: A case study. IET Gener. Transm. Distrib. 2018, 12, 2487-2495. [CrossRef]

3. Piotrowski, T.; Rozga, P.; Kozak, R. Comparative analysis of the results of diagnostic measurements with an internal inspection of oil-filled power transformers. Energies 2019, 12, 2155. [CrossRef]

4. Li, E.; Wang, L.; Song, B. Fault Diagnosis of Power Transformers with Membership Degree. IEEE Access 2019, 7, 28791-28798. [CrossRef]

5. Piotrowski, T. Effectiveness assessment of selected graphical techniques for the interpretation of measured concentrations of gases dissolved in transformer oil. Prz. Elektrotechniczny 2019, 95, 57-60. [CrossRef]

6. Cheim, L.; Duval, M.; Haider, S. Combined Duval Pentagons: A simplified approach. Energies 2020, 13, 2859. [CrossRef]

7. Irungu, G.K.; Akumu, A.O. Application of dissolved gas analysis in assessing degree of healthiness or faultiness with fault identification of in oil-immersed equipment. Energies 2020, 13, 4770. [CrossRef]

8. CIGRE. Transformer Bushing Reliability; Technical Brochure 755; CIGRE: Paris, France, 2019.

9. Malpure, B.D.; Chaudhari, S.E. Importance of bushing-DGA in condition assessment of power transformers. In Proceedings of the 2012 IEEE International Conference on Condition Monitoring and Diagnosis, Bali, Indonesia, 23-27 September 2012. [CrossRef]

10. Mohseni, B.; Hashemnia, N.; Islam, S. Condition assessment of power transformer bushing using SFRA and DGA as auxiliary tools. In Proceedings of the 2016 IEEE International Conference on Power System Technology (POWERCON), Wolongong, NSW, Australia, 28 September-1 October 2016. [CrossRef]

11. Schuette, T.; Santos, E. Understanding the Breakdown Mechanism of Bushings and Implementing Appropriate Life-Cycle Oriented Maintenance Strategies, TechCon AsiaPacific, Sydney, Australia, 12-13 April 2016. Available online: https://pdfs.semanticscholar.org/58b0/7efaa1008f0ee29b7a38fd776cde306c08ed.pdf (accessed on 11 November 2020).

12. Zhou, D.; Ma, Z.; Cai, L.; Yang, X.; Ou, X.; Lin, C.; Ouyang, X. Experience Gained in Fault Diagnosis and Tear-down Analysis of Transformer Bushings. In Proceedings of the 2019 IEEE 3rd International Electrical and Energy Conference (CIEEC), Beijing, China, 7-9 September 2019; pp. 1691-1694. [CrossRef]

13. Enciso, L.; Alvarez, R.; Martinez, J.L.; Arce, P.; Galliani, M.; Rodriguez, P.; Calo, E. Incipient failures analysis of high voltage bushings. In Proceedings of the 2020 IEEE Electrical Insulation Conference (EIC), Knoxville, TN, USA, 22 June-3 July 2020; pp. 68-71. [CrossRef]

14. IEC 60599. 2015 Mineral Oil-filled Electrical Equipment in Service-Guidance on the Interpretation of Dissolved and Free Gases Analysis; International Electrotechnical Commission: Geneva, Switzerland, 2015.

15. Energopomiar-Elektryka. Framework Instruction of Transformer Operation (FITO); Energopomiar-Elektryka: Gliwice, Poland, 2012. (In Polish)

16. CIGRE. Advances in DGA Interpretation; Technical Brochure 771; CIGRE: Paris, France, 2019.

17. Kazmierski, M.; Olech, W. Technical Diagnosis and Transformer Monitoring; Energopomiar-Elektryka: Gliwice, Poland, 2013. (In Polish)

18. Duval, M. A review of faults detectable by gas-in-oil analysis in transformers. IEEE Electr. Insul. Mag. 2002, 18, 8-17. [CrossRef]

19. Beauchemin, C. DGA Tools: Duval Triangles and Pentagons. In Proceedings of the International Transformer Conference, Transformator'17, Torun, Poland, 9-11 May 2017.

Publisher's Note: MDPI stays neutral with regard to jurisdictional claims in published maps and institutional affiliations. 